\title{
A Study of the Impact of Underground Economy on Integral Tax Burden in the Proportional Growth Model under Uncertainty
}

\author{
Akif Musayev $\mathbb{D}^{1,2}$ and Aygun Musayeva ${ }^{3}$ \\ ${ }^{1}$ Institute of Economics, Azerbaijan National Academy of Sciences, Baku, Azerbaijan \\ ${ }^{2}$ Near East University, Nicosia, Northern Cyprus, Mersin 10, Turkey \\ ${ }^{3}$ Azerbaijan University, Baku, Azerbaijan \\ Correspondence should be addressed to Akif Musayev; akif.musayev@gmail.com
}

Received 3 August 2017; Accepted 15 February 2018; Published 1 April 2018

Academic Editor: Rafik Aliev

Copyright (C) 2018 Akif Musayev and Aygun Musayeva. This is an open access article distributed under the Creative Commons Attribution License, which permits unrestricted use, distribution, and reproduction in any medium, provided the original work is properly cited.

\begin{abstract}
Economic processes are naturally characterized by imprecise and uncertain relevant information. One of the main reasons is existence of an underground economy. However, in existing works, real-world imprecision and uncertainty of economic conditions are not taken into account. In this paper we consider a problem of calculation of a taxation base to assess tax burden for proportionally growing economy under uncertainty. In order to account for imprecision and uncertainty of economic processes, we use the theory of fuzzy sets. A fuzzy integral equation is used to identify an integral tax burden taking into account the contribution of the underground economy for a certain financial (tax) year. It is also assumed that dynamics of gross domestic product are modeled by fuzzy linear differential equation. An optimal value of tax burden is determined as a solution to the considered fuzzy integral equation. An example is provided to illustrate validity of the proposed study.
\end{abstract}

\section{Introduction}

The current stage of economic development is characterized by the influence of several fundamental factors. In scientific literature these factors are divided into clusters according to their nature, stages, coverage, and so on.

According to Balatsky [1] these factors split into three groups: generality, uncertainty, and economic impact. It has been noted that they have formed new producing capacity by influencing the structure of the economic system, the norms, and trends in the economy.

One of the important factors of economic development is the tax burden of the economy. Economic entities transmit a portion of their income to state or local self-governing bodies in the form of taxes. This transfer of financial resources limits the ability of consumers to choose between products and ability of producers to choose between production factors, thus creating additional burden on economic entities.

Determining the tax burden in line with the reality formed by the economic system is one of the most difficult problems. It is connected with the fact that the tax system should cover the public needs and on the other hand stimulate the interests of taxpayers in entrepreneurial activity.

In this sense, the tax burden is considered as the quality of the country's tax system and the overall business environment.

The study of the impact of the tax burden on economic activity and the state's financial strength remains the most pressing issue of economics and economic policy. In ages of globalization, this problem attracts attention of economics experts as well as institutions of different countries.

Public administration and legislation system also have a significant impact on economic growth due to share of overall consumption in gross domestic product (GDP), aggregate investment, public spending, and net exports. For example, the introduction of a new taxation regime to fixed capital investment and repatriation of income in tax legislation can affect transfer of new technologies, research, and development works as well as import-export processes.

It is well known that the tax burden of economy is expressed in terms of separate taxes established by tax 
legislation and at the same time as an integral quantitative expression of the cumulative effects of these taxes (integral $\operatorname{tax})$.

In modern economic literature, depending on the purpose of the research, the tax burden is differentiated by the maximum, average, actual, effective consumption, public expenditure, and the increase in tax rates. There are various approaches to calculating the tax burden. In practice, the most commonly used approach by the public tax policy institutions is to set the tax burden as a ratio of aggregated tax revenues to GDP.

Generally, these approaches are described in various scientific bibliographies. For example, in [2] the tax rates are described as marginal rate, final tax rate, and economic (effective) tax rate.

At the microlevel, the tax burden of an economic entity is determined as the rate of paid taxes to the total income gains arising from product produced and the service rendered. It is also possible that the tax burden is determined as the ratio of the amount of taxes paid to the tax base.

The literature review allows coming to conclusion that all above-mentioned approaches are far from a universal one. In this regard, identification of this particular economic factor remains an important issue of modern economic research.

Looking at the economic growth theories in the historical context, the first remembering theory is of mercantilism (15th-17th centuries). The theory of mercantilism shows the accumulation of wealth (gold and other precious metals) as the main source of economic growth [3]. In the following period, neoclassical economists criticized the New Keynesians, argued that the cause of economic growth was not just in the frame of unused production factors, but also technological advances, and increased productivity through innovations in production management. Neoclassical economists believed that economic growth would be achieved in a free market economy. The theory proposed by the Nobel Prize winner Robert Solow based on the Cobb-Douglas production function also linked three main sources of economic growth: investments, workforce, and technological progress [4]. Along with this model, saving rate plays a key role in forming capital reserves and increasing production.

In the 1980-1990s, significant progress was observed in economic growth theories. This trend was announced as a "new economic theory." Economists have examined some weaknesses of the neoclassical economists, in particular the Solow model, and made proposals to increase the impact of the government to long-term economic growth. According to the Solow model, the impact of the government on economic growth is considered as very insignificant. However, adherers of the endogenous economic growth theory suppose that scientific and technological progress plays a crucial role for economic growth as endogenous factors. Romer $[5,6]$ and Lucas Jr. [7] argue that technological innovations are primarily due to technology development and human capital investment. Technological progress in endogenous growth theories is considered as the only viable cause of economic growth in the long-term perspective. Similar reasons were raised in theories of Grossman and Helpman [8] and Aghion and Howitt [9].
In [10] the tax burden and economic development in case of the EU countries are discussed. There are different methods for evaluation tax burden and economic development. These include such research methods as systematic, logical, and comparative analysis. Statistical methods are also used in including descriptive statistics, hierarchical cluster analysis, and correlation analysis. Empirical analysis is based on the data of the EU countries. It is shown that the tax burden on capital and consumption is higher in the very high economic development countries, but implicit tax rate on capital is higher in the case of countries with lower GDP growth.

It is known that the excess burden of taxation shows efficiency cost associated with taxation. In [11] excess burden is measured by the area of the associated Harberger triangle [12]. Excess burden task is discussed in Arnold Harberger's pioneering work in the 1960s which measured the costs of tax distortions to labor supply, saving, and other economic decisions $[13,14]$.

Using a simple input-output model, in [15] the author estimates the revenue impact, US tax burden, state-by-state impact of this proposal on tax burdens, employment, and economic output. Also authors show that elimination of the deduction for the oil and gas industry would result in higher corporate tax burdens for domestic oil and gas companies compared to other US manufacturing industries. In reality, US oil and gas companies could not hope to keep pace with competitors in countries with lower tax rates. Moreover, increasing corporate taxes on the US energy sector increase the costs of production and may reduce the resources.

Determination of the optimal size of tax burden is very important and difficult scientific and practical problem. The main goal of [16] is to determine the optimal of tax burden for the economy of Georgia. Optimally determined taxes can play very important role for sustainable development of economics. For this reason author used qualitative, quantitative, correlation/regression analysis. Tax burden for the economy of Georgia depends on size and type of activities of enterprises and should range from $13.6 \%$ to $17.6 \%$

The influence of optimal tax burden on economic activity and production capacity is discussed in [17]. In this paper the tax policy and an optimal tax burden are described.

Let us mention that information related to economic processes is naturally characterized by uncertainty and imprecision due to a series of reasons one of which is existence of an underground economy. In this paper we consider a problem of calculation of a taxation base to assess tax burden for proportionally growing economy under uncertainty. In order to account for imprecision and uncertainty of economic processes, we use the theory of fuzzy sets. A fuzzy integral equation is used to identify an integral tax burden taking into account the impact of the underground economy for a certain financial (tax) year. An example is provided to prove validity of the proposed study.

The paper is organized as follows. In Section 2 we provide a preliminary material to be used in the study including a definition of a fuzzy number-valued function, integral of a fuzzy number-valued function, and other concepts. In Section 3 we describe the proposed fuzzy approach to identify an integral tax burden taking into account the contribution 
of the underground economy. A method to assess impact of underground economy is described in Section 4. An example illustrating the proposed fuzzy approach is considered in Section 5. Section 6 concludes.

\section{Preliminaries}

Denote $E^{1}$ is the set of fuzzy numbers defined over the real line $\mathrm{R}$.

Definition 1 (a fuzzy number-valued function [18, 19]). A mapping $\tilde{f}: T \rightarrow E^{1}$ is referred to as a fuzzy number-valued function of a real variable.

Definition 2 (see $[18,19]$ ). A function $\tilde{f}: T \rightarrow E^{1}$ is referred to as integrably bounded if there exists such realvalued function $h$ that $\|x\| \leq h(t), \forall x \in \operatorname{supp} \widetilde{f}(t)$.

A definition of measurability of a fuzzy number-valued function of a real variable is given in [18]. In [18] it is shown that strongly measurable and integrably bounded fuzzy number-valued function is integrable.

Definition 3 (an integral of a fuzzy number-valued function [18]). Let $\tilde{f}: T \rightarrow E^{1}$. An integral of $\tilde{f}$ on $T=[a, b]$ denoted as $\int_{T} \tilde{f}(t) d t$ or $\int_{a}^{b} \tilde{f}(t) d t$ is defined in terms of $\alpha$-cuts as follows:

$$
\begin{aligned}
& {\left[\int_{T} \tilde{f}(t) d t\right]^{\alpha}=\int_{T} f^{\alpha}(t) d t=\left\{\int_{T} \varphi(t) d t, \varphi: T\right.} \\
& \left.\quad \longrightarrow R^{n} \text { - measurable choice for } f^{\alpha}\right\}, \quad \forall \alpha \in(0,1] .
\end{aligned}
$$

Definition 4 (strongly generalized differentiability [20]). Let $\tilde{f}:(a, b) \rightarrow E^{1}$ and $t_{0} \in(a, b)$. We say that $\tilde{f}$ is strongly generalized differentiable at $t_{0}$ if there exists an element $\widetilde{f}^{\prime}\left(t_{0}\right) \in E^{1}$; such that,

(i) for all $\Delta t>0$ sufficiently small, $\exists \widetilde{f}\left(t_{0}+\Delta t\right)-{ }_{h} \tilde{f}\left(t_{0}\right)$, $\widetilde{f}\left(t_{0}\right){ }_{-}{ }_{h} \widetilde{f}\left(t_{0}-\Delta t\right)$ (i.e., the length of $\operatorname{diam}\left((f(t))^{\alpha}\right)$ increases), and the limits (in the supremum metric $[18,19]$ )

$$
\begin{aligned}
& \lim _{\Delta t \rightarrow 0^{+}} \frac{\tilde{f}\left(t_{0}+\Delta t\right)-{ }_{h} \tilde{f}\left(t_{0}\right)}{\Delta t}=\lim _{\Delta t \rightarrow 0^{+}} \frac{\tilde{f}\left(t_{0}\right)-{ }_{h} \tilde{f}\left(t_{0}-\Delta t\right)}{\Delta t} \\
& \quad=\tilde{f}^{\prime}\left(t_{0}\right)
\end{aligned}
$$

or

(ii) for all $\Delta t>0$ sufficiently small, $\exists \tilde{f}\left(t_{0}\right)-{ }_{h} \tilde{f}\left(t_{0}+\right.$ $\Delta t), \tilde{f}\left(t_{0}-\Delta t\right)-{ }_{h} \tilde{f}\left(t_{0}\right)$ (i.e., the length of $\operatorname{diam}\left((f(t))^{\alpha}\right)$ decreases), and the limits (in the supremum metric $[18,19])$

$$
\begin{aligned}
& \lim _{\Delta t \rightarrow 0^{+}} \frac{\tilde{f}\left(t_{0}\right){ }_{h} \tilde{f}\left(t_{0}+\Delta t\right)}{(-\Delta t)}=\lim _{\Delta t \rightarrow 0^{+}} \frac{\tilde{f}\left(t_{0}-\Delta t\right)-{ }_{h} \tilde{f}\left(t_{0}\right)}{(-\Delta t)} \\
& =\widetilde{f}^{\prime}\left(t_{0}\right) .
\end{aligned}
$$

${ }_{{ }_{h}}$ denotes Hukuhara difference.
Definition 5 (possibility measure [21, 22]). Given two fuzzy sets defined in the same universe of discourse $X$, a fundamental question arises as to their similarity or proximity. There are several well-documented approaches covered in the literature. One of them concerns a possibility measure. The possibility measure, denoted by $\operatorname{Poss}(\widetilde{A}, \widetilde{X})$, describes a level of overlap between two fuzzy sets and is expressed in the form

$$
\operatorname{Poss}(\widetilde{A}, \widetilde{X})=\sup _{x \in X}[A(x) \wedge X(x)],
$$

where $\Lambda$ is a $t$-norm. Computationally, we note that the possibility measure is concerned with the determination of the intersection between $\widetilde{A}$ and $\widetilde{X}$, that is followed by the optimistic assessment of this intersection. It is done by picking up the highest values among the intersection grades of $\widetilde{A}$ and $\widetilde{X}$ that are taken over all elements of the universe of discourse $X$.

\section{Fuzzy Model of a Tax Burden}

First, let us provide an explanation of important economic indicators considered in the paper.

As a rule, a tax burden $u$ is defined as the following ratio:

$$
u=\frac{T}{\xi K},
$$

where $T$ is tax revenue and $\xi K$ is equity capital load taking into account taxes.

A tax burden leads to an economic system transition from $y(t)$ state to $y_{1}(t)$ state. Assume that, at the beginning of a considered year, GDP depends on a value of a fixed capital:

$$
K_{i p(t)}=P_{(t-1)}\left(K_{i p(t-1)}-R_{i p(t-1)}-A_{(t-1)}\right),
$$

where $R_{i p}$ is investment; $A=\theta K$ depreciation-amortization of $K$ value loaded share of core capital; $\theta$ is amortization rate; $P$ is deflator.

It is obvious that information related to some parameters of underground economy and economic growth in general is imprecise. Thus, it is more adequately to use fuzzy models for describing tax burden in such conditions.

A tax burden $u(t)$ leads to an economic system transition from fuzzy state $\tilde{y}(t)$ to fuzzy state $\widetilde{y}_{1}(t)$

$$
\tilde{y}_{1}(t)=u(t) \tilde{y}(t) .
$$

Let us use the following terms and symbols: $t$ is financial (taxation) year; $\widetilde{y}(t)$ is the income of the economic system from the production and service rendered by the business; $\tilde{y}_{1}(t)$ is posttax income of an economic entity; $u(t)$ is the tax burden of the economic entity in the financial (tax) year; $\xi$ is equity capital load taking into account the taxes; $\tilde{\lambda}$ is the fuzzy value of the growth rate of the economy; $\widetilde{\eta}$ is the fuzzy value of the underground economy weight; $\tau$ is period for tax liabilities. The following fuzzy equation comes from economic balance conditions:

$$
\int_{0}^{\tau}\left[\tilde{y}(t)-\widetilde{y_{1}}(t)\right] d t=(1+\widetilde{\eta}) \xi
$$


or

$$
\int_{0}^{\tau}[\tilde{y}(t)-u(t) \tilde{y}(t)] d t=(1+\widetilde{\eta}) \xi .
$$

Now we need to analyze the form of $\tilde{y}(t)$. As we consider proportional economic growth model under fuzzy environment, dynamics of $\tilde{y}$ can be adequately described by the following fuzzy differential equation [18-20] under (ii) type of strongly generalized differentiability (Definition 4) [20]

$$
\frac{d \tilde{y}}{d t}=\tilde{\lambda} \tilde{y}
$$

It is known that the solution of (10) is

$$
\tilde{y}=\tilde{y}_{0} e^{\tilde{\lambda} t}
$$

which can be described in $\alpha$-cuts as follows:

$$
\begin{aligned}
& y_{1}^{\alpha}=y_{01}^{\alpha} e^{\lambda_{1}^{\alpha} t}, \\
& y_{2}^{\alpha}=y_{02}^{\alpha} e^{\lambda_{2}^{\alpha} t} .
\end{aligned}
$$

Thus, given solution (11) we can transform (9) into the following integral equation:

$$
\int_{0}^{\tau}(1-u(t)) e^{\tilde{\lambda} t} d t=\xi(1+\tilde{\eta}) .
$$

Given the obtained fuzzy model of tax burden, we need to consider a problem of determination of $u(t)$ that solves (13). We will consider determination of $u(t)$ in the class of constant functions $u(t)=u, u=$ const. As (13) is fuzzy, the equality of the left and the right hand sides should be considered in terms of a degree. As a measure of a degree of equality, we will use the possibility measure. Then the considered problem can be formulated as follows:

$$
\begin{aligned}
& P\left(\int_{0}^{\tau}(1-u(t)) e^{\tilde{\lambda} t} d t, \xi(1+\widetilde{\eta})\right) \rightarrow \max \\
\text { s.t. } & u(t)=u, \\
& u=\text { const, }
\end{aligned}
$$

where $P$ is the possibility measure. In other words, it is needed to find such a value of $u=$ const for which the possibility measure of equality of the left and the right hand sides is maximal.

\section{Experts' Group Opinion Based Estimation of the Impact of Underground Economy on Tax Burden}

Experience has shown that comprehensive indicators of an economy system are not quite precise due to uncertainty of major factors. One of the most important of these factors is the weight of the underground economy. It is of particular importance if one takes into account comprehensive burden for the economy. No wonder assessing of this factor is in focus of major modern surveys.

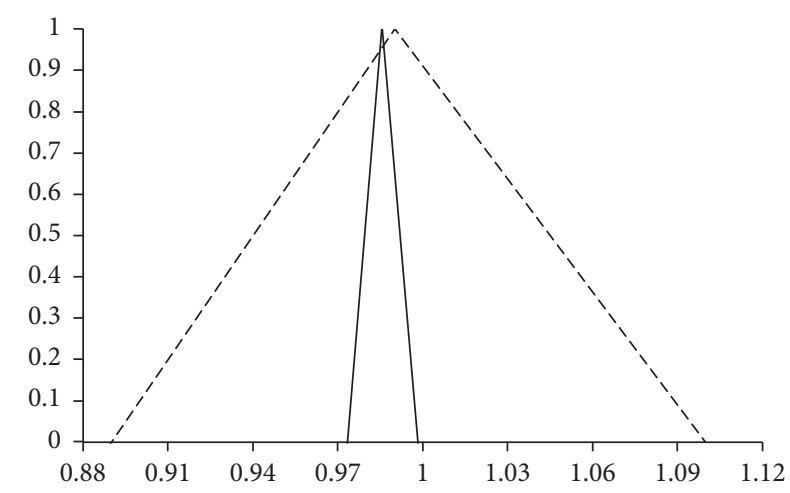

FIGURE 1: The fuzzy values of the left hand side (dashed curve) and the right hand sides (solid curve) of (14).

In [23] the theoretical approaches to the definition of the hidden economy taxation base are widely analyzed, specified into three groups, and recommended to use the volume of GDP as the tax base. However, there is no comment on how to determine the specific weight of the hidden economy. Obviously, the problem of determining both the specific weight of hidden economy and tax base comprised its tax burden is one of the pending problems.

In this study, the load factor of the main capital, determining the loaded part of the fixed capital $\xi$, is specified by the quantity $\tilde{\eta}$. As an underground economy is of latent character, an adequate estimation of its impact $\tilde{\eta}$ can be based on experts' opinions described in natural language and formalized by using fuzzy sets.

The opinion of expert group on the impact of changes in tax legislation on tax revenue is computed by using a weighted average based aggregation:

$$
\widetilde{\eta}=\frac{\sum_{i=1}^{n} \widetilde{q}_{i} \cdot \widetilde{w}_{i}}{\sum_{i=1}^{n} \widetilde{w}_{i}}, \quad i=1, \ldots, n,
$$

where $\tilde{q}_{i}$ is a fuzzy evaluation of $\tilde{\eta}$ provided by $i$ th expert and $\widetilde{w}_{i}$ is a fuzzy confidence degree of $i$ th expert.

\section{An Example}

Consider the following example. Let and $\tilde{\lambda}=(1.0 ; 3.0 ; 5.0)$ be a triangular fuzzy number (TFN) describing fuzzy value of the growth rate of hypothetic economy, let $\widetilde{\eta}=$ $(0.32 ; 0.34 ; 0.35)$ be a TFN describing expert group-based computed by using (16), and $\xi=0.737 ; \tau=1$ in (13). It can be shown that the left hand side of (13) is an integrable fuzzy number-valued function of a real variable. Thus, we can consider a problem (14) to determine $u$. By using numerical techniques, we have found $u=0.15$ as the solution of (14) which provides $P\left(\int_{0}^{\tau}(1-u(t)) e^{\tilde{\lambda} t} d t, \xi(1+\widetilde{\eta})\right)=$ 0.96 . This value of possibility measure can be considered as sufficiently suitable from practical point of view. The left part of (13) approximated by TFN $\int_{0}^{\tau}(1-u(t)) e^{\tilde{\lambda} t} d t=$ $(0.89,0.99,1.1)$ and the right part described by TFN $\xi(1+\widetilde{\eta})=$ $(0.9733 ; 0.9857 ; 0.9982)$ are shown in Figure 1. 


\section{Conclusion}

In this paper we use fuzzy integral equation to model the way tax burden induces transition of state of economy. An optimal value of tax burden is considered as a solution to fuzzy integral equation. The use of fuzzy sets helps to model imprecise information including experts' opinion based evaluation of an underground economy weight. An example is used to illustrate the proposed approach. In the example, a tax burden $u=15$ is found as a solution to the fuzzy integral equation with possibility degree 0.96 . The obtained result shows validity of the proposed study.

\section{Conflicts of Interest}

The authors declare that they have no conflicts of interest.

\section{References}

[1] Y. V. Balatsky, "A mechanism of dependence between innovations and economic growth," Science, Innovations and Education, vol. 2, pp. 182-198, 2007 (Russian).

[2] I. A. Mayburov, Theory of Taxation. Advanced Course, Unity, Moscow, Russia, 2011.

[3] J. McDermott, "Mercantilism and modern growth," Journal of Economic Growth, vol. 4, no. 1, pp. 55-80, 1999.

[4] R. M. Solow, "A contribution to the theory of economic growth," Quarterly Journal of Economics, vol. 70, pp. 56-94, 1956.

[5] P. M. Romer, "Increasing returns and long-run growth," Journal of Political Economy, vol. 94, no. 5, pp. 1002-1037, 1986.

[6] P. M. Romer, "Endogenous technological change," Journal of Political Economy, vol. 98, no. 5, pp. S71-S102, 1990.

[7] R. E. Lucas Jr., "On the mechanics of economic development," Journal of Monetary Economics, vol. 22, no. 1, pp. 3-42, 1988.

[8] G. M. Grossman and E. Helpman, "Endogenous innovation in the theory of growth," The Journal of Economic Perspectives, vol. 8, no. 1, pp. 23-44, 1994.

[9] P. Aghion and P. W. Howitt, The economics of growth, MIT press, 2008.

[10] L. Sineviciene, "Tax burden and economic development: the case of the European Union Countries," in Entrepreneurship, Business and Economics, vol. 2, pp. 283-298, Springer International Publishing Switzerland, 2016.

[11] J. R. Hines, Excess Burden of Taxation. Working Paper Series, University of Michigan and NBER, 2007, Product Number WP 2007-1.

[12] J. R. Hines Jr., “Three sides of Harberger triangles," Journal of Economic Perspectives (JEP), vol. 13, no. 2, pp. 167-188, 1999.

[13] A. C. Harberger, "The measurement of waste," American Economic Review, vol. 54, pp. 58-76, 1964.

[14] A. C. Harberger, "Taxation, resource allocation, and welfare," in The role of Direct and Indirect Taxes in the Federal Revenue System, John F. D. and N. J. Princeton, Eds., pp. 25-70, Princeton University Press, 1964.

[15] A. Chamberlain, "Estimating the Tax Burden and Economic Impact from the Proposed "Gang of Ten" Revenue Offsets," in Fiscal Economics Policy Study 2008-08, Institute for Energy Research, 2008, http:/www.instituteforenergyresearch.org/ wp-content/uploads/2008/09/gang_of_10_energy_study.pdf.
[16] T. Kbiladze, "Theoretical and Empirical Basis of Optimal Tax Burden in Georgia," International Journal of Trade, Economics and Finance, vol. 6, no. 6, pp. 314-317, 2015.

[17] G. Abuselidze, "The influence of optimal tax burden on economic activity and production capacity," Intellectual Economics, vol. 6, no. 4, pp. 493-503, 2012.

[18] P. Diamond and P. Kloeden, Metric Spaces of Fuzzy Sets: Theory and Applications, World Scientific, Singapore, 1994.

[19] V. Lakshmikantham and R. Mohapatra, Theory of Fuzzy Differential Equations and Inclusions, Taylor \& Francis, London, NY, USA, 2003.

[20] B. Bede and S. G. Gal, "Generalizations of the differentiability of fuzzy-number-valued functions with applications to fuzzy differential equations," Fuzzy Sets and Systems, vol. 151, no. 3, pp. 581-599, 2005.

[21] R. A. Aliev and R. R. Aliev, Soft Computing and Its Applications, World Scientific, Singapore, New Jersey, USA, London, UK, Hong Kong, 2001.

[22] W. Pedrycz, Knowledge Based Clustering. from Data to Information Granules, John Wiley \& Sons, Hoboken, NJ, USA, 2005.

[23] I. A. Mayburov, "Methodological aspects of study of an impact of underground economy to assesment of tax burden," Audit News, vol. 9, pp. 50-62, 2012, in Russian. 


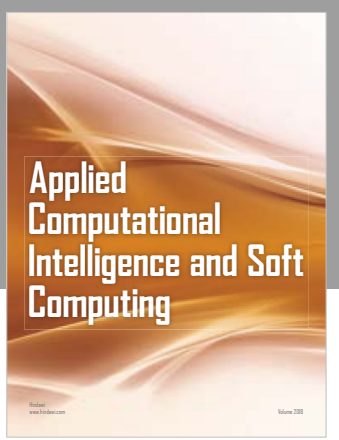

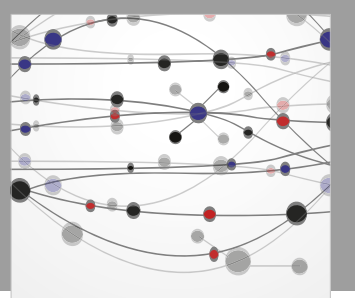

The Scientific World Journal
Submit your manuscripts at

Computing
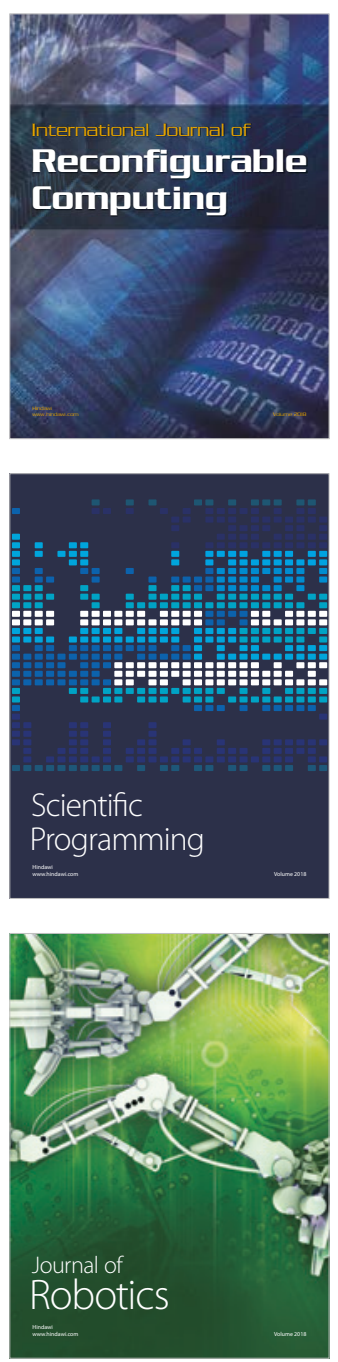

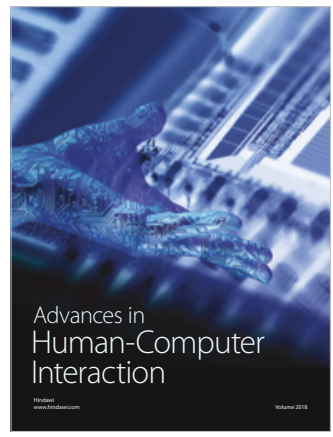

Human-Compute

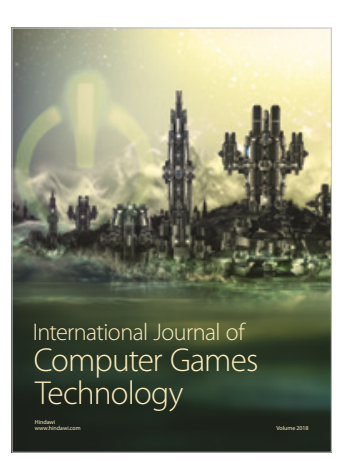

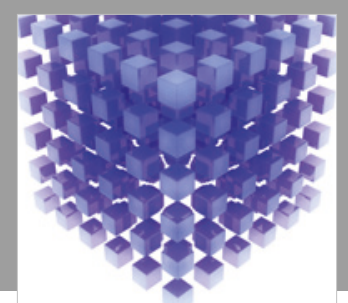

Mathematical Problems in Engineering

\section{Engincering}
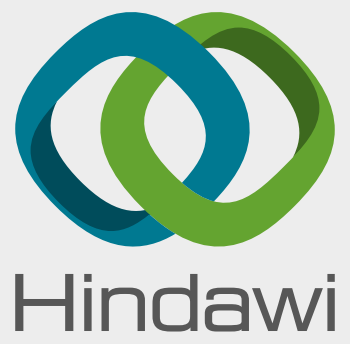

www.hindawi.com
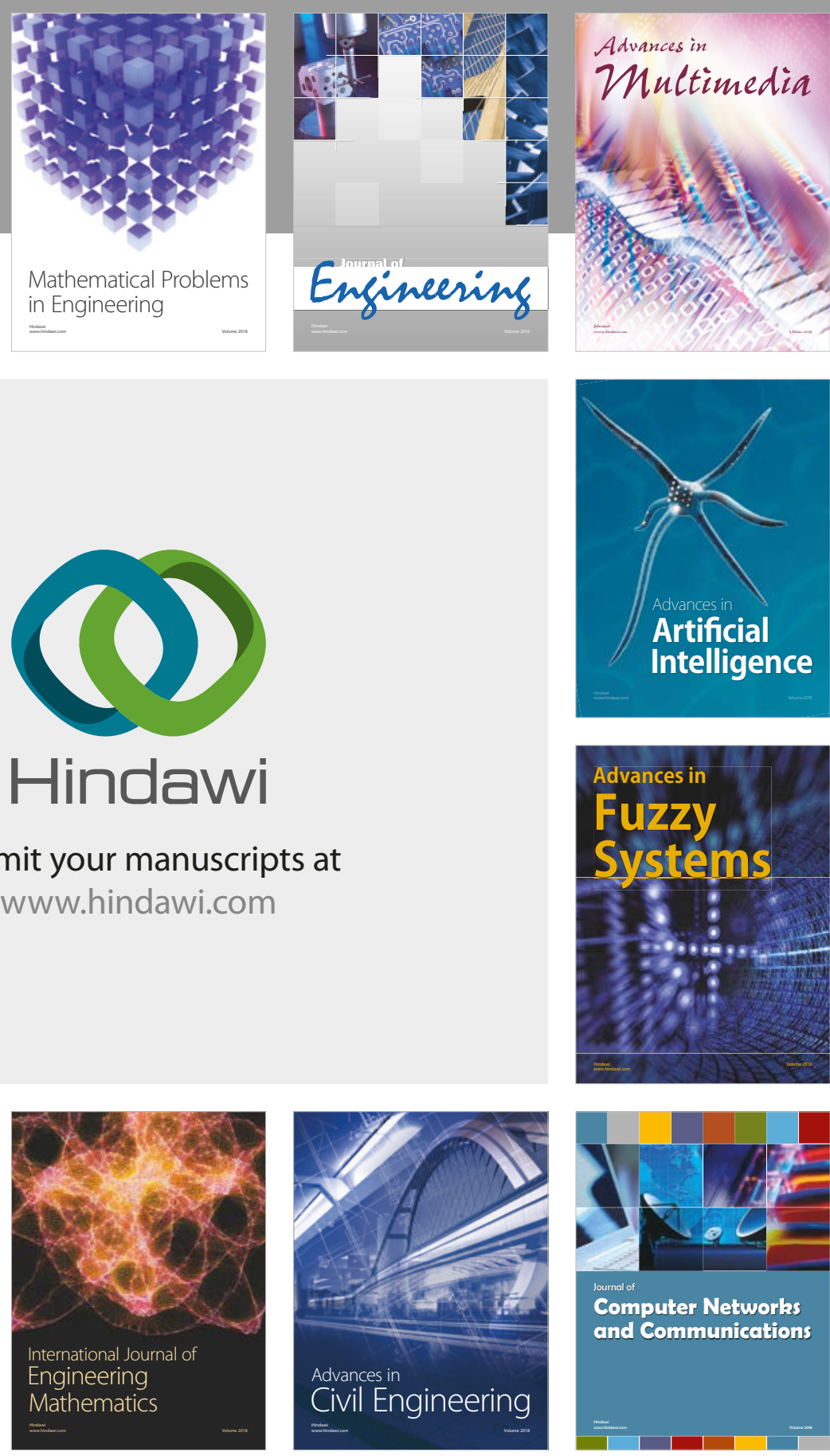

Computer Networks and Communications

Multimedia
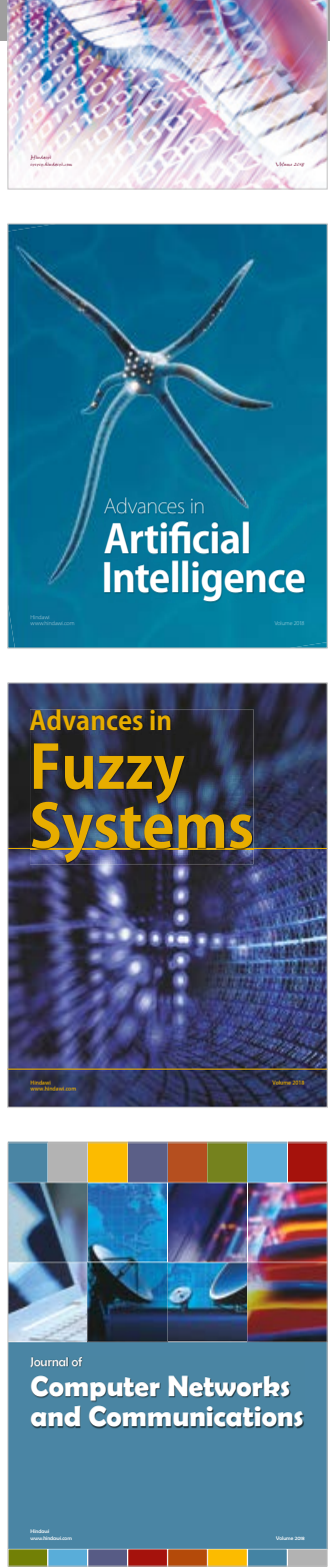

Advances in

Modelling \&

Simulation

in Engineering

interaction

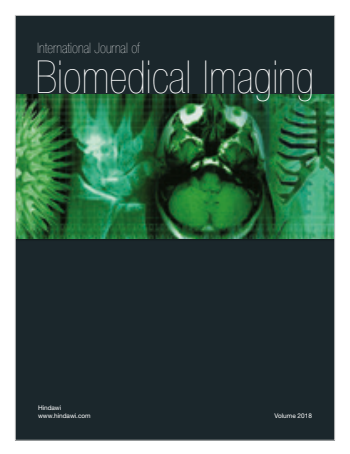

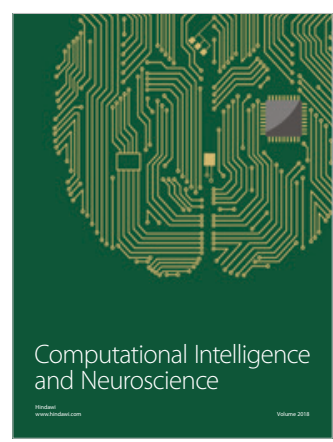

